\title{
Curcumin-A Review of Its Antibacterial Effect
}

\author{
Kai Kai ${ }^{1}$, Wanling $\mathrm{Bi}^{1}$, Yukun $\mathrm{Bo}^{2}$, Yingwang $\mathrm{Ye}^{1}$ and Danfeng Zhang ${ }^{1 *}$ \\ ${ }^{1}$ School of Food and Biological Engineering, China \\ ${ }^{2}$ Animal Husbandry Technology Promotion Institution of Zhangjiakou, China \\ *Corresponding author: Danfeng Zhang, School of Food and Biological Engineering, China
}

\section{ARTICLE INFO}

Received: 幽 February 18, 2020

Published: 幽 February 26, 2020

Citation: Kai Kai, Wanling Bi, Yukun Bo, Yingwang Ye,Danfeng Zhang. Curcumin-A Review of Its Antibacterial Effect. Biomed J Sci \& Tech Res 26(1)-2020. BJSTR. MS.ID.004286.

\section{ABSTRACT}

Curcumin is the main active component in Curcuma longa rhizome that is being recognized and used worldwide in many different forms for its multifunctional properties. A range of studies have reported the antimicrobial activity of curcumin, including antibacterial, antiviral, and antifungal activities. Here, we discuss the antibacterial activity and the action mode of curcumin, as well as the strategies to improve its bioavailability.

Keywords: Curcumin; Antibacterial Activity; Bioavailability

\section{Mini Review}

Curcumin, a polyphenol extracted from the rhizome of Curcuma longa, is in interest of researchers worldwide in recent years due to its various biological activities. It has been traditionally used in Asian countries in different products, including colorants, curries, tea, and cosmetics [1]. In some area, it is also used as medicine, due to its antioxidant, anti-inflammatory [2], antimicrobial [3], and anticancer activities [4]. Curcumin has been reported to have broad-spectrum antimicrobial activity against bacteria [5], viruses [6], and fungi [7]. In this review, we provide a brief overview of the studies regarding the antibacterial activity and the antibacterial action mode of curcumin, as well as the approaches for the improvement of its bioavailability.

\section{Inhibitory Effect of Curcumin on Pathogenic Bacteria}

Curcumin inhibits endodontic bacterial strains of Streptococcus mutans, Actinomyces viscosus, Lactobacillus casei, Porphyromonas gingivalis, Prevotella intermedia, Enterococcus faecalis, with MIC values of 333.33, 167.67, 125, 125, and $208.33 \mathrm{mg} / \mathrm{L}$, respectively [8]. The $S$. mutans biomass and its biofilm formation can be effectively inhibited by the application of curcumin [9]. Similar results are also observed on several periodontopathic bacteria, including Fusobacterium nucleatum and Treponema denticola, which were suppressed by curcumin in a dose dependent manner [10]. Curcumin is 32 -fold more potent than fluconazole in the inhibition of the growth of Paracoccidioides brasiliensis [11], which is the pathogen that causes one of the most prevalent systemic mycoses in Latin America - paracoccidioidomycosis [12]. Curcumin shows an inhibitory property against some food borne pathogenic and spoilage bacteria such as Escherichia coli, Yersinia enterocolitica, Streptococcus aureus, Bacillus subtilis, and B. cereus [13]. The inhibitory effect is also observed on Listeria monocytogenes and Salmonella typhimurium [14].

Using the curcumin as a complementary compound in combination with other existing medicines to control bacteria growth has attracted attentions from researchers. The application of the combination of subtilosin with curcumin on L. monocytogenes infection reaches a lower effective dose compared with the utilization of subtilosin alone [15]. Synergistic effect of curcumin and antibiotics oxacillin, ampicillin, ciprofloxacin, or norfloxacin used against methicillin-resistant $S$. aureus infection is confirmed by Mun et al. [16]. Curcumin combined with (-)-epigallocatechin gallate notably reduces the biofilm formation in wastewater bacteria [17].

The activation of photosensitive substances by light in the presence of oxygen results in the production of reactive radicals, which are capable of inducing cell death. The effect of photosensitization mediated by curcumin on bacteria inhibition 
has been investigated. Curcumin at the concentration of $75 \mu \mathrm{M}$ in combination with a blue LED effectively inhibits the growth of S. aureus, Aeromonas hydrophila, S. typhimurium, E. coli, and Pseudomonas aeruginosa [18]. S. mutans and Lactobacillus acidophilus are reported to be sensitive to curcumin in the presence of blue light; however, the utilization of curcumin in the dark was not toxic to the bacteria [19].

\section{Action Mode of Curcumin against Bacteria}

Membrane Disruption: Studies show that curcumin inhibited bacteria by damaging bacterial membrane. A membrane permeabilization assays confirms that the addition of curcumin results in membrane leakage in both Gram-negative and Grampositive bacteria, including $S$. aureus, Enterococcus faecalis, E. coli, and P. aeruginosa [5]. However, according to the study of Yun et al. [20], curcumin induces membrane damage at relatively high concentrations, but there is no effect at the MIC.

Reactive Oxygen Species (ROS) Induction: Curcumin significantly inactivates $B$. cereus and $E$. coli by inducing significant production of ROS, including singlet oxygen and hydroxyl radicals [21]. At the MIC $(12 \mu \mathrm{g} / \mathrm{mL})$, curcumin-treated cells display various apoptotic markers, including ROS accumulation, membrane depolarization, and $\mathrm{Ca}^{2+}$ influx [20].

Efflux Pump Inhibition: Curcumin is reported to function as an efflux pump inhibitor in a multi drug resistant pathogenic bacteria $P$. aeruginosa [22]. Similar result was also been observed by Eshra et al. [23]. Joshi et al. [24] also suggested that curcumin inhibits several bacterial efflux pumps in S. aureus effectively.

Cell Division Interuption: Curcumin has been shown to inhibit bacterial cell proliferation by perturbation of FtsZ assembly in the B. subtilis 168, suggesting that it inhibits bacterial cytokinesis [25]. The study on E. coli and B. subtilis by Kaur et al. [26] also demonstrated that curcumin suppress the FtsZ assembly, leading to disruption of prokaryotic cell division. Moreover, curcumin decrease the production of extracellular polysaccharide in the short term. The expression of genes related to extracellular polysaccharide synthesis, carbohydrate metabolism, adherence decreased after curcumin treatment [9].

\section{Enhancement of the Bioavailability of Curcumin}

Though curcumin has been considered as a promising antibacterial agent and has the potential to be used for clinical treatment, one of the major problems with ingesting curcumin by itself is its poor bioavailability, which appears to be primarily due to poor absorption, rapid metabolism, and rapid elimination [27]. Enhancing the bioavailability of curcumin has received rather concerns in recent years. Using some agents to form a curcumin complex has been tested to improve the bioavailability of curcumin. For instance, piperine enhances the bioavailability of curcumin by 20 folds [28]. Microemulsions of curcumin fabricated from food-grade ingredients, such as Tween 20, lecithin, vitamin E, and ethanol, in- crease the water dispersibility of curcumin by 1,000 to 10,000 folds [29]. Nanocurcumin has also been considered as an alternative to improve the bioavailability of curcumin [30]. Curcumin nanoparticle with the size of 2-40 nm exhibits more significant antimicrobial activity against $S$. aureus, E. coli, and P. aeruginosa [31]. Encapsulation of curcumin in liposomes enhances its water dispersibility and increases its chemical stability, water dispersibility and antioxidant and anti-inflammatory properties [29].

\section{Conclusion}

The extensive antimicrobial effects of curcumin against pathogenic bacteria suggest it has the potential to be considered as a candidate for the clinical therapies of bacterial infections. Exploration of the action mode of curcumin against bacteria and strategies that are developed to enhance the curcumin bioavailability to improve its application effects become the focuses of researches.

\section{Conflicts of Interest}

The authors declare no conflict of interest.

\section{Acknowledgement}

The authors would like to thank the Fundamental Research Funds for the Central Universities (JZ2019HGTB0067).

\section{References}

1. Hewlings SJ, Kalman DS (2017) Curcumin: A review of its' effects on human health. Foods 6(10).

2. Menon VP, Sudheer AR (2007) Antioxidant and anti-inflammatory properties of curcumin. Advances in Experimental Medicine and Biology 595: 105-125.

3. Moghadamtousi SZ, Kadir HA, Hassandarvish P, Tajik H, Abubakar S, et al. (2014) A review on antibacterial, antiviral, and antifungal activity of curcumin. BioMed Res Int pp. 186864.

4. Hatcher H, Planalp R, Cho J, Torti FM, Torti SV (2008) Curcumin: From ancient medicine to current clinical trials. Cell Mol Life Sci 65(11): 16311652.

5. Tyagi P, Singh M, Kumari H, Kumari A, Mukhopadhyay K (2015) Bactericidal activity of curcumin I is associated with damaging of bacterial membrane. PLoS One 10(3): e0121313.

6. Mathew D, Hsu WL (2018) Antiviral potential of curcumin. J Funct Foods 40: 692-699.

7. Lee W, Lee DG (2014) An antifungal mechanism of curcumin lies in membrane-targeted action within Candida albicans. IUBMB Life 66(11): 780-785.

8. Mandroli PS, Bhat K (2013) An in-vitro evaluation of antibacterial activity of curcumin against common endodontic bacteria. J Appl Pharm Sci 3(10): 106-108.

9. Li B, Li X, Lin H, Zhou Y (2018) Curcumin as a promising antibacterial agent: effects on metabolism and biofilm formation in S. mutans. BioMed Res Int pp. 4508709.

10. Izui S, Sekine S, Maeda K, Kuboniwa M, Takada A, et al. (2016) Antibacterial activity of curcumin against periodontopathic bacteria. J Periodontol 87(1): 83-90.

11. Martins CVB, Da Silva DL, Neres ATM, Magalhães TFF, Watanabe GA, et al. (2009) Curcumin as a promising antifungal of clinical interest. J Antimicrobial Chemother 63(2): 337-339. 
12. Borges Walmsley MI, Chen D, Shu X, Walmsley AR (2002) The pathobiology of Paracoccidioides brasiliensis. Trends Microbiol 10(2): 80-87.

13. Wang Y, Lu Z, Wu H, Lv F (2009) Study on the antibiotic activity of microcapsule curcumin against foodborne pathogens. Int J Food Microbiol 136(1): 71-74.

14. Altunatmaz SS, Aksu FY, Issa G, Kahraman BB, Altiner DD, et al. (2016) Antimicrobial effects of curcumin against L. monocytogenes, $S$. aureus, $S$. Typhimurium and E. coli 0157: H7 pathogens in minced meat. Vet Med 61(5): 256-262.

15. Amrouche T, Noll KS, Wang Y, Huang Q Chikindas ML (2010) Antibacterial activity of subtilosin alone and combined with curcumin poly-lysine and zinc lactate against Listeria monocytogenes Strains. Probiotics Antimicrobial Proteins 2(4): 250-257.

16. Mun SH, Joung DK, Kim YS, Kang OH, Kim SB, et al. (2013) Synergistic antibacterial effect of curcumin against methicillin-resistant Staphylococcus aureus. Phytomedicine 20(8-9): 714-718.

17. Lade H, Paul D, Kweon JH (2015) Combined effects of curcumin and $(-)$-epigallocatechin gallate on inhibition of $\mathrm{N}$-acylhomoserine lactonemediated biofilm formation in wastewater bacteria from membrane bioreactor. J Microbiol Biotechnol 25(11): 1908-1919.

18. Penha CB, Bonin E, Da Silva AF, Hioka N, Zanqueta EB, et al. (2016) Photodynamic inactivation of foodborne and food spoilage bacteria by Curcumin. LWT - Food Sci Technol 76: 198-202.

19. Araújo NC, Fontana CR, Bagnato VS, Gerbi MEM (2014) Photodynamic antimicrobial therapy of curcumin in biofilms and carious dentine. Lasers Med Sci 29(2): 629-635.

20. Yun DG, Lee DG (2016) Antibacterial activity of curcumin via apoptosislike response in Escherichia coli. Appl Microbiol Biotechnol 100(12): 5505-5514.

21. Xu CS, Ip M, Leung AWN, Wang XN, Yang ZR, et al. (2018) Sonodynamic bactericidal activity of curcumin against foodborne bacteria. Hong Kong Med J 24 Suppl 6(5): 43-44.

\section{ISSN: 2574-1241}

DOI: $10.26717 /$ BJSTR.2020.26.004286

Danfeng Zhang. Biomed J Sci \& Tech Res

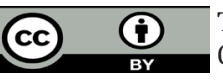

This work is licensed under Creative Commons Attribution 4.0 License

Submission Link: https://biomedres.us/submit-manuscript.php
22. Negi N, Prakash P, Gupta ML, Mohapatra TM (2014) Possible role of curcumin as an efflux pump inhibitor in multi drug resistant clinical isolates of Pseudomonas aeruginosa. J Clin Diagn Res 8(10): DC04-DC07.

23. Eshra KA, Shalaby MM (2017) Efflux pump inhibition effect of curcumin and phenylalanine arginyl $\beta$-naphthylamide $(\mathrm{PA} \beta \mathrm{N})$ against multidrug resistant Pseudomonas aeruginosa isolated from burn infections in Tanta University hospitals. Egypt J Med Microbiol 26(1): 113-119.

24. Joshi P, Singh S, Wani A, Sharma S, Jain SK, et al. (2014) Osthol and curcumin as inhibitors of human Pgp and multidrug efflux pumps of Staphylococcus aureus: Reversing the resistance against frontline antibacterial drugs. Med Chem Commun 5: 1540-1547.

25. Rai D, Singh JK, Roy N, Panda D (2008) Curcumin inhibits FtsZ assembly: an attractive mechanism for its antibacterial activity. Biochem J 410(1): 147-155.

26. Kaur S, Modi NH, Panda D, Roy N (2010) Probing thebinding site of curcumin in Escherichia coli and Bacillus subtilis FtsZ-a structural insight to unveil antibacterial activity of curcumin. Eur J Med Chem 45(9): 42094214.

27. Anand P, Kunnumakkara AB, Newman RA, Aggarwal BB (2007) Bioavailability of curcumin: Problems and promises. Mol Pharm 4(6): 807-818.

28. Patil VM, Das S, Balasubramanian K (2016) Quantum chemical and docking insights into bioavailability enhancement of curcumin by piperine in pepper. J Phys Chem A 120(20): 3643-3653.

29. Sanidad KZ, Sukamtoh E, Xiao H, McClements DJ, Zhang G (2019) Curcumin: Recent advances in the development of strategies to improve oral bioavailability. Annu Rev Food Sci Technol 10: 597-617.

30. Shaikh J, Ankola DD, Beniwal V, Singh D, RaviKumar MNV (2009) Nanoparticle encapsulation improves oral bioavailability of curcumin by at least 9-fold when compared to curcumin administered with piperine as absorption enhancer. Eur J Pharm Sci 37(3-4): 223-230.

31. Bhawana B, Basniwal RK, Buttar HS, Jain VK, Jain N (2011) Curcumin nanoparticles: preparation, characterization, and antimicrobial study. J Agric Food Chem 59(5): 2056-2061.

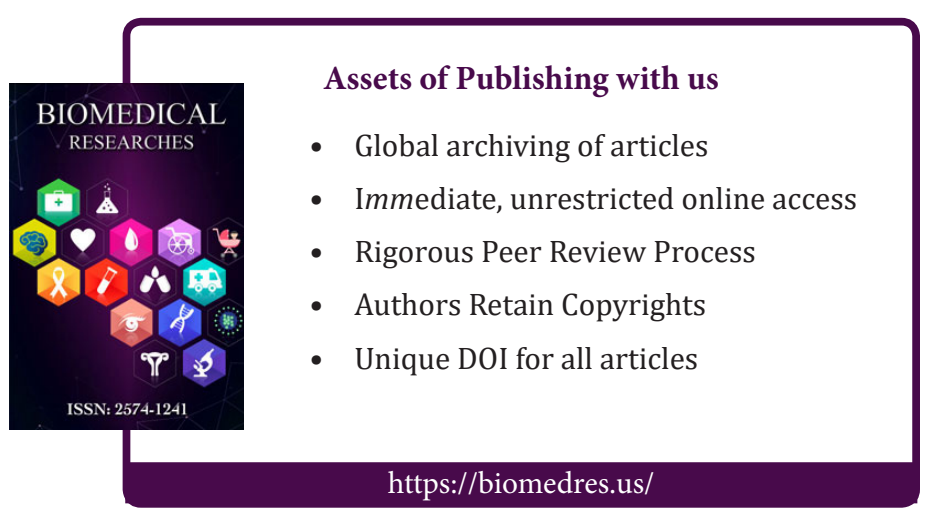

